RBEn 28: 42-47, 1975

\title{
INTEGRAÇĀO ENSINO E SERVIÇO DE ENFERMAGEM PARTICIPAÇÃO DO INPS NA INTEGRAÇÃO SERVIÇO - ESCOLA
}

\author{
Edla Dalva Moreira*
}

RBEn/03

MOREIRA, E. D. - Integração Ensino e Serviço de Enfermagem do INPS na Integração Serviço-Escola. Rev. Bras. Enf.; Rio de Janeiro, 28: 42-47, 1975.

"O estudo dos recursos humanos para as atividades de saúde deve ser feita com uma dupla visão: a da formação e a da utilização" (1).

Essas duas visões não devem ser dissociadas para que o produto final - o profissional de saúde - possa deixar o sistema formador em condições de assumir, na força de trabalho do País, o verdadeira papel que lhe compete.

O INPS, como maior utilizador dos recursos humanos para a saúde, está participando, de modo crescente, da integração entre os serviçcs assistenciais e as escolas formadoras de profissionais da Equipe de Saúde.

A atual política do Governo no campo social - congregando no Conselho de Desenvolvimento Social todos os Ministérios com vinculação aos problemas de saúde - vem colaborar para que essa integração se faça cada vez mais efetiva.

As alterações que estão se processando no âmbito da Previdência Social condicionam e propiciam essa integração que visa colaborar com a política do Governo para a formação de recursos humanos necessários ao desenvolvimento do País como um todo não só sob o aspecto econômico como social.

Atual política assistencial do Ministério da Previdência e Assistência Social (MPAS).

A estratégia do Governo no campo da saúde atribui ao MPAS "ação voltada para o atendimento médico-assistencial individualizada, cuja expansão progressiva exige atuação prioritária, fundada em programação flexível, coerente e conjugada de todos os agentes prestadores de assistência médico-sanitária" (2).

O Ministério, nas su.as proposições para as diferentes áreas - Previdência Social, Assistência Médica e Assistência Social- tem procurado valorizar o homem, objeto dos planos de ação do atual Governo.

$\mathrm{Na}$ área da assistência médica destxcamos das suas diretrizes: (3).

* Chefe de Equipe de Enfermagem da Secretaria de Assistência Médíca do INPS. 
MOREIRA, E. D. - Integração Ensino e Serviço de Enfermagem do INPS na Integração Serviço-Escola. Rev. Bras. Enf.; Rio de Janeiro, 28: 42-47, 1975.

a) universalização da assistência, colocando-a à disposição de todcs;

b) adequação dos hospitais próprios à alta especialização, à pesquisa e ao aperfeiçoamento;

c) racionalização do funcionamento dos serviços, com vista à melhoria do padrão;

d) integração da medicina preventiva às atividades curativas;

e) possibilidade de financiamento às empresas de saúde para ampliação de instalações e aquisição de equipamentos - visando melhorar o atendimento aos beneficiários;

f) apoio aos programas de treinamento funcional;

g) convênios com os hospitais de ensino para o atendimento aos beneficiários.

Os convênios com os hospitais de ensino, resultaram de um Protocolo assinado $\mathrm{em} 1974$ pelo Ministro da Previdência e Assistência Social e o Ministro da Educação e Cultura "objetivando a integração cos hospitais de ensino nos programas de assistência médica da Previdência Social".

De acordo com a minuta-padrão do referido convênio o INPS pagará mensalmente, ao hospital de ensino, uma taxa correspondente ao número de altas hospitalares - taxa essa variável, de acordo com o tipo do atendimento: clínico, cirúrgico, obstétrico ou ambulatorial.

\section{Atuação do INPS, operacionando as diretrizes do MAPS e promovendo a execução}

O Programa de Ação para o INPS em 1975(4) atende à política do Governo. consubstanciada nas diretrizes do MAPS e procura atingir objetivos gerais e específicos.

São seus objetivos gerais:

a) melhorar e expandir os serviços; b) melhorar a imagem do INPS.

Entre os objetivos específicos de cacia linha de atividade, cabe destacar aqueles relacionados à assistência médica:

a) melhorar a funcionalidade das unidades médico-assistenciais próprias e das contratadas e a sua capacidade de atencimento;

b) elevar o padrão de atendimento médico-assistencial;

c) individualizar o atendimento, tornando-o o mais humanizado possível;

d) preparar pessoal para gerência dos estabelecimentos próprios;

e) melhorar o relacionamento com outras entidades públicas e privadas que atuem no setor.

O INPS vem executando esse programa seja diretamente ou através de supervisão e controle de organismos públicos ou privados, procurando simplificar as ações operacionais, liberando recursos, descentralizando, aplicando modernização administrativa e métodos empresariais - conforme preconizado no II Plano Nacional de Desenvolvimento.

Todas as providências que vem sendo tomadas, entretanto, ainda não conseguiram modificar a imagem do INPS conforme se deseja; a complexidade e o gigantismo da Instituição dificultam uma rápida mudança, que necessita de um trabalho constante, permanente de todos, durante muito tempo.

\section{A perspectiva da instituição do Sistema Nacional de Saúde (SNS)}

A integração de todos os Ministérios que participam da prevenção das doencas e da recuperação da saúde, em um Sistema Nacional de Saúde, será a solucão para a dispersão de recursos e a sunerposição de serviços existentes no País.

Sistema de Saúde, segundo define a OMS (5), é um mecanismo pelo qual os recursos humanos e a capacidade ins- 
MOREIRA, E. D. - Integração Ensino e Serviço de Enfermagem do INPS na Integração Serviço-Escola. Rev. Bras. Enf.; Rio de Janeiro, 28: 42-47, 1975.

talada se organizam, através de estrutura administrativa e de uma tecnologia médica, para oferecer prestação de serviços de saúde integrados em quantidade suficiente e qualidade adequada".

O Sistema Nacional de Saúde (6) - a ser coordenado pelo Conselho de Desenvolvimento Social - será constituído de três subsistemas:

1. ${ }^{\circ}$ - Saneamento e controle do meio ambiente, cuja meta será a erradicação das endemias;

2.0 - Prestação de serviço de saúde individual, que deverá reorganizar os serviços médicos até 1979, levando a assistência às regiões desprotegidas.

Os serviços médicos deverão constituir uma rede assistencial, tendo como centro os hospitais de ensino, integrados a hospitais de base - distritais - os quaiss, por sua vez, estarão ligados às Unidades Sanitárias, que deverão existir em todos os municípios.

3. ${ }^{\circ}$ Subsistema - Atividades de apoio que têm por metas:

a) melhorar a formação do pessoal;

b) promover a criação de um sistema básico de estatística de saúde.

Aos Ministérios integrantes do Sistema competirá:

I - Ministério da Saúde:

"- formular a Política Nacional de Saúde e promover ou executar ações preferencialmente voltadas para as medidas e os atendimentos de interesse coletivo..."

II - Ministério de Educação e Cultura:

"- promover a formação e habilitação dos profissionais de nível universitário; assim como o do pessoal técnico e auxiliar, necessário ao setor saúde..."

III - Ministério do Interior:
"- promover saneamento, radicação das populações, desenvolvimento regional integrado e assistência em caso de calamidade pública"...

IV - Ministério do Trabalho:

“- promover a higiene e segurança do trabalho, a prevenção de acidentes e de doenças profissionais, a proteçāo, a disciplina cooperativa e a política salarial das profissões de saúde..."

$\mathrm{V}$ - Ministério da Previdência e Assistência Social:

"- promover e executar o atendimento médico assistencial individualizado, cabendo-lhe particularmente:

A) Elaborar planos de prestação de serviços de saúde às pessoas;

B) Coordenar no âmbito Nacional, o subsistema de prestação de serviços de saúde às pessoas;

C) Credenciar, para integrarem o subsistema público, instituições de finalidades não lucrativas que prestam serviços de saúde às pessoas;

D) Prestar diretamente serviços de saúde às pessoas ou contratá-las com entidades de fins lucrativos ou nāo, sujeitando-as à fiscalização permanente;

E) Experimentar novcs métodos terapêuticos e novas modalidades de prestação de assistência, avaliando su.a melhor adequação às necessidades do País;

F) Fixar, em colaboração com o $\mathrm{Mi}$ nistério da Saúde, normas e padrões para a prestação de serviços de saúce a pessoas, a serem observadas pelas entidades vinculadas ao Sistema;

G) Promover medidas adequadas à redução do custo dos medicamentos de maior eficácia e de comprovada necessidade para a proteção da saúde e combate às doenças, inclusive, suibvencionando a sua aquisição e distribuindo-o gratuitamente às classes mais pobres da população".

Além dos Ministérios diretamønte vinculados ao Sistema, serão por ele coordenados, os programas de outros Ministé- 
MOREIRA, E. D. - Integração Ensino e Serviço de Enfermagem do INPS na Integração Serviço-Escola. Rev. Bras. Enf.; Rio de Janeiro, 28: 42-47, 1975.

rios, quando relacionados à saúde, tais como:

a) controle de migrações, realizado pelo INGRA (Ministério da Agricultura) migrações que muitas vezes concorrem para a disseminação de endemias e epidemias;

b) controle do seguro saúde (Ministério da Indústria e Comércio);

c) controle de tarifas e importação de bens e produtos para a área de saúde (Ministério da Fazenda).

Os Estados, Distrito Federal, Territórios e Municípios, "receberão incentivos técnicos e financeiros da União para que organizem seus serviços, atividades e programas de saúde segundo as diretrizes da Política Nacional de Saúde".

Em documento apresentado ao Conselho de Desenvolvimento Social, pelo MPAS - e que forneceu subsídio para a elabcração do Projeto de Lei que institui o Sistema Nacional de Saúde é sugerida a criação de uma instituição para administrar a prestação de serviços de saúde individual, com autonomia comparável a das empresas de economia mista.

Essa providência já autorizada pelo Sr. Presidente da República, está sendo estudada na área do MPAS, com vistas à criação da FUNAME (Fundação Nacional de Assistência Médica), organização que englobará os serviços médicos assistenciais da Previdência Social e será a responsável pelo $2 .^{\circ}$ subsistema do Sistema Nacional de Saúde - "a prestação de serviços de saúde individual”.

\section{Situação atual do interrelacionamento INPS/Escolas}

A nova política assistencial exige, mais do que nunca, recursos humanos adequados - em qualidade e quantidade para a viabilização das metas a atingir, considerando que a escassez desses re- cursos repercute sobre o desenvolvimento econômico-social e o bem-estar da ccletivicade (8).

As "Recomendações" formuladas na III Reunião Especial de Ministros de Saúde das Américas, realizada no Chile em 1972, orientam que deve ser alcancada em 1980 uma proporção de 19 elementos de enfermagem para 10.000 habitantes, sendo que desse grupo 4,5/10.000 habitantes deverão ser enfermeiros.

Nessa Reunião o Brasil se propôs a formar, até 1980 cerca de 150.000 profissionais de enfermagem a nível de $1 .^{\circ}$ grau e de, aproximadamente, 85.000, a níveis de $2 .^{\circ}$ e $3 .^{\circ}$ graus (médio e superior).

Além desse aspecto quantitativo há que ser observada também a qualidade do profissional a ser formado atendendo às necessidades do mercado de trabalho e às possibilidades de sua utilização .

No planejamento dos recursos humanos deve-se pois ter em mente números (quantidade) e imagem (qualidade). (1)

Conhecendo-se a problemática da formação de pessoal no País, conclui-se que uma Instituição como o INPS - que precisa de quantidade e qualidade não poderia deixar de participar do esforço governamental para incrementar a formação de recursos humanos para o setor saúde.

Sendo ele o maior mercado de trabalho do País nos seus serviços próprios e agente de influência para ampliação do mercado nas instituições particulares convenientes não poderia ficar à margem da formação profissional, pelo seu próprio interesse em obter profissionais qualificados e identificados com a sua realidade assistencial.

A integração entre o INPS e as escolas de enfermagem processa-se atualmente através de dois mecanismos:

a) convênios com os hospitais de en- 
MOREIRA, E. D. - Integração Ensino e Serviço de Enfermagem do INPS na Integração Serviço-Escola. Rev. Bras. Enf.; Rì de Janeiro, 28: 42-47, 1975.

sino, para atendimento dos beneficiários, convênios esses que indiretamente beneficiam os estudantes, pois ampliam as oportunidades de estágio nos próprios hospitais universitários que terão aumentada a sua taxa de ocupação, pelo aproveitamento da capacidade ociosa. (7)

b) convênios ccm as escolas de enfermagem para estágio de estudantes nas Unidades Médico-Assistenciais do INPS: os quais passaram por uma fase de defasagem, estando, entretanto, em franca expansão.

A experiência tem demonstrado a validade da medida, apesar de alguns problemas, como a restrição imposta pelas normas vigentes no INPS sobre o assunto, (8) com referência ao acompanhamento dos estagiários por professores da escola - por ser considerado inadmissível a interferência de pessoas estranhas nas atividades assistenciais.

Para solucionar esse problema está sendo estudada a possibilidade de aproveitamento pelas Escolas, em caráter provisório, de enfermeiros do INPS com experiência em magistério - os quais serviriam de ponte de ligação, para um melhor entrosamento.

Por outro lado, tem-se procurado conscientizar os enfermeiros do INPS da sua responsabilidade como educadores e da possibilidade que terão de influenciar na formação de profissionais que mais tarde irão, certamente, integrar a equipe dos nossos próprios serviços e, que melhor produzirão se melhor forem preparados.

Tem sido incentivada a participação dos enfermeiros em cursos de Licenciatura, o que concorrerá para mudança de atitude em face do problema.

Além disso está sendo estudada a fixação dos critérios de retribuição dos enfermeiros do INPS que participam da orientação e supervisão do alunos (8), como uma forma de incentivo.
A par desses mecanismos, já atuantes, estão sendo estudados dois outros que consideramos de grande importância para a integração cio INPS ao campo do ensino:

a) criação pelo INPS de cursos de auxiliar de enfermagem, nos Estados onde dispõem de hospitais próprics, para, principalmente, transformar os Atendentes e Auxiliares de Serviços Médicos - hoje Auxiliares Operacionais de Serviços Diversos - em Auxiliares de Enfermagem;

b) instituição de estágios para enfermeiros recém-formadcs - à semelhança do Sistema de Residência - sem, entretanto, fornecer hospedagem, por falta de área física em nossos hospitais objetivando facilitar a adaptação do profissional às suas novas atribuições, pois sabemos serem grandes os problemas encontrados ao entrarem diretamente no campo de trabalho sem o necessário período de ajustamento (9) .

Essa será a nossa parcela de colaboração para um problema que todos estamos sentindo - falta de ajustamento profissional.

Sabemos que essa parcela mínima não será capaz de solucionar o problema que deve ter raízes mais profundas e que merecem ser pesquisadas, cabe-nos apenas alertar as Escolas, repetindo o que diz Mário Chaves (1): "Deve-se procurar adequar a formação à função que deve ser desempenhada. É tão mau o subtreinamento quanto o supertreinamento. Ambos levam a frustrações e a problemas emocionais. O indivíduo responsável subtreinado procura fugir de situações em que possa defrontar-se com tarefas que são esperadas dele e para as quais não foi preparado..."

"O indivíduo supertreinado, sente-se diminuído, frustrado, quando confinado a tarefas que poderiam ser feitas por pessoas de nível educacional e ocupacional inferior". 
MOREIRA, E. D. - Integração Ensino e Serviço de Enfermagem do INPS na Integração Serviço-Escola. Rev. Bras. Enf.; Rio de Janeiro, 28: 42-47, 1975.

Como vimos, há que se encontrar o ponto de equilíbrio, adequando a formação às funções que o profissional irá desempenhar, sem descurar que deverá, também, saber executar para que possa observar e supervisionar.

Ainda é Mário Chaves quem nos diz - "Dentro de um conceito sistêmico, não é possível aceitar um currículo feito internamente, dentro do aparelho formador, com base na idéia construída pelos professores do que o profissional deve ser. Tal currículo ideal deve ser substituído por um currículo real, apoiado na realidade do sistema de saúde e expresso em termos de objetivos de comportamento" (1) .

No panorama atual da assistência médica previdenciária novos horizontes continuam se abrindo para a enfermagem, seja no campo de serviço, ou no campo de ensino, o que considero promissor, pois o ideal seria que todos os enfermeiros tivessem oportunidade de atuar nas duas áreas, que se interligam e se completam, uma vez que o professor não deve ter apenas uma visão teórica do que ensina e o enfermeiro, que atua na assistência, não pode deixar de ser um educador, devendo sempre transmitir o melhor de si ao educando, seja diretamente ou pelo exemplo.

Ambos são responsáveis não só pela formação dos novos profissionais, como pela sua própria formação, ao longo da vida, pois que essa formação é um processo contínuo, permanente, não sendo o enfermeiro, em tempo algum, um produto acabado, necessitando sempre de atualização, de reciclagem.

Outra responsabilidade que devemos assumir é pela imagem da profissão na comunidade, para isso devemos todos enfermeiros de serviço e de ensino nos unirmos para não deixar morrer a chama de ideal que norteou a criação da enfermagem científica em nosso País

\section{REFERÊNCIAS BIBLIOGRÁFICAS}

1. Anteprojeto de Resolução instituindo estágio para enfermeiros nas Unidades Médico-Assistenciais do INPS.

2. CHAVES, Mário M. - Saúde e Sistemas - F.G.V. págs. 111, 123, 134 e 135.

3. La Planificación Sanitária Nacional en los paises en desarrollo - OMS - Genebra - 1967.

(Série de Informes Técnicos 350).

4. Portaria MPAS - 39/74 - Plano de Pronta Ação.

5. Projeto de Lei que institui o Sistema Nacional de Saúde.
6. Protocolo firmado entre o MPAS e MEC e a Minuta-Padrão de Convênio entre os Serviços de Assistência Médico-Hospitalar com os Hospitais Universitários e de Ensino.

8. Stephanes, Reinhold - Programa de ação para o INPS 1975.

9. Resolução INPS 399.5/70 Orientação de Serviço SAM - n. 35:9.33/70 e Instrução de Serviço SAM - n. 399.17/70.

10. II Plano Nacional de Desenvolvimento'. 